\title{
Epistemología de la crisis: apuntes zavaletianos sobre coyuntura chilena y andina
}

Epistemology of the Crisis: the Chilean and Andean Situation Through a Zavaleta Mercado's Framework of Analysis

\section{Felipe Lagos-Rojas}

\section{(2) OpenEdition}

\section{Journals}

Edición electrónica

URL: http://journals.openedition.org/transtexts/1301

DOI: 10.4000/transtexts.1301

ISSN: 2105-2549

\section{Editor}

Gregory B. Lee

\section{Referencia electrónica}

Felipe Lagos-Rojas, «Epistemología de la crisis: apuntes zavaletianos sobre coyuntura chilena y andina », Transtext(e)s Transcultures 跨文本跨文化 [En ligne], 14 | 2019, mis en ligne le 31 décembre 2019, consulté le 28 juillet 2020. URL : http://journals.openedition.org/transtexts/1301 ; DOI : https:// doi.org/10.4000/transtexts. 1301

Este documento fue generado automáticamente el 28 julio 2020.

(c) Tous droits réservés 


\title{
Epistemología de la crisis: apuntes zavaletianos sobre coyuntura chilena y andina
}

\author{
Epistemology of the Crisis: the Chilean and Andean Situation Through a Zavaleta \\ Mercado's Framework of Analysis
}

Felipe Lagos-Rojas

\section{Introducción}

El año 2019 nos dejó un mapa sociopolítico latinoamericano en el que resalta la franja andina, en un proceso de ajuste de placas sociales que promete tener alcances continentales, si bien desiguales o asincrónicos, y cuyo epicentro actual solo recientemente se ha desplazado desde la región andina hacia los Estados Unidos. ${ }^{1} \mathrm{El}$ núcleo de este artículo estará puesto en el proceso Chile, pero se hacen necesarias asimismo referencias al proceso boliviano, así como alusiones a otros países del continente.

2 Recurro a las conceptualizaciones del marxista boliviano René Zavaleta Mercado como centro de gravedad de este escrito, por dos motivos. En primer lugar, tanto Bolivia como Perú forman parte de ese evento fundacional a la identidad chilena que fue la Guerra del Pacífico (1879-1883), en una relación que se complementa con aquel otro acontecimiento fundante de la nación, la Guerra de Arauco liberada sin tregua por el Estado chileno contra el pueblo Mapuche. ${ }^{2}$ La coincidencia de ambos en el tiempo permite considerar este momento en base a lo que Zavaleta llamó "momento constitutivo" (categoría a la que será necesario volver en lo que sigue), y que tal vez es el motivo a la base de que el pensamiento crítico producido en esos dos países haya tenido tanto impacto en la izquierda chilena, partiendo por el ejemplar ejercicio que iniciara José Carlos Mariátegui al problematizar la traducción directa del sujeto 
proletario a la realidad latinoamericana, en un gesto que resultó seminal para aquello que conocemos como marxismo latinoamericano. ${ }^{3}$

3 Además de este motivo histórico, tenemos también el hecho de que la complejidad de las reflexiones de Zavaleta acerca del estado y la democracia (reflexiones que en muchos sentidos resultan anticipatorias de lo que proponemos entender grosso modo como "estado neoliberal") resultan relevantes para comprender la actual coyuntura andina. No es casual destacar a este respecto el hecho de que el marxismo de Zavaleta encontró su primera formulación en el análisis de los procesos chileno y boliviano de mediados del siglo XX, análisis que quedara registrado en el libro El poder dual publicado en México en 1974. Partícipe él mismo de muchas de las vicisitudes vividas por intelectuales marxistas entre los años sesenta y ochenta, a través de su marxismo Zavaleta no necesitó fetichizar la categoría de democracia para ofrecer una lectura política acerca de la generalización autoritaria en el continente. Entiende y deja claro que democracia no significa en principio más que la forma normalizada, hegemónica, de la dictadura de clase del capital, materializada y reproducida por medio de su estado. ${ }^{4}$ Mi escrito busca mostrar que, por la vía de esta dialéctica entre forma democrática y sustancia dictatorial, el aparato conceptual de Zavaleta permite dar cuenta de importantes aspectos del dominio de clase en el capitalismo tardío dependiente: "La dictadura es el carácter del Estado. No sólo un incidente de concentración del recurso estatal sino un elemento constitutivo del Estado como tal. No significa ello otra cosa que el límite de todo poder político que alcance densidad estatal es siempre su causa final, es decir, su naturaleza de clase". ${ }^{5}$

\section{Modelo vertical autoritario, o fascismo como modalidad del estado neoliberal ${ }^{6}$}

4 La crisis abierta en Chile es expresiva de un proceso que no permite ser circunscrito a su irrupción inmediata, gatillada por el alza del transporte y otros servicios básicos en la región metropolitana de Santiago. Se trata antes bien de una erupción que, primero, venía fraguándose recientemente desde diversos movimientos y organizaciones, ${ }^{7}$ y que además ha logrado poner en jaque la institucionalidad política (y en ese sentido merece ser considerado como un momento prerrevolucionario). La reacción autoritaria presenciada durante los últimos meses y concentrada entre el 18 de octubre de 2019 y el marzo de 2020, no es sino expresión concreta del temor que causa al orden neoliberal la plebe como multitud en acción. Y, en lo que en el marco del tiempo "normal" (el tiempo de la política como monopolio del estado) era ya considerado como democracia "tutelada" o "de baja intensidad", en momentos de excepción muestra su aspecto propiamente dictatorial. Fueron condiciones de dictadura las que permitieron hacer de Chile un laboratorio neoliberal, y son estas condiciones las que reaparecen en el momento más apremiante para la defensa del régimen. ${ }^{8}$

Entiendo por neoliberalismo algo parecido a lo que Lenin entendió por imperialismo, esto es, una fase superior en el desarrollo capitalista a escala planetaria, que incluye tanto un nuevo nivel de infraestructura productiva (la que comienza con la dimensión digital, central para la financiarización de la economía global) como también nuevas técnicas de restauración del poder de clase del capital y de transformación "molecular" (la imagen es de Gramsci) de un conjunto creciente de aspectos de la vida social, con énfasis en la despolitización de la sociedad, la fragmentación de identidades colectivas 
y la creciente administración de los cuerpos. Estas nuevas técnicas han flexibilizado la extracción de capital e intensificado la acumulación por desposesión, haciendo uso de políticas de shock como mecanismos de ajuste a nivel económico tanto como ideológico. 9

En un sugerente artículo de 1979, titulado "Notas sobre fascismo, dictadura y coyuntura de disolución", Zavaleta indica que el fascismo ha devenido una forma interior o inherente al estado capitalista. Propone distinguir entre fascismo como proyecto político, como movimiento de masa y como estructura de poder. ${ }^{10} \mathrm{En}$ este último sentido, sugiere nuestro autor que, aun con prescindencia de sus elementos como proyecto ideológico explícito de refundación social o como movilización de masas, se evidencia una disposición del estado a asumir una modalidad fascista en momentos de excepción, por cuanto "el fascismo es una forma anómala que se produce dentro del tipo de Estado capitalista". ${ }^{11}$ En un registro complementario con dicho análisis, Zavaleta escribe en 1982 el artículo "Problemas de la determinación dependiente y la forma primordial", donde vincula la categoría de fascismo dependiente acuñada por Theotonio dos Santos con lo que él mismo propone llamar "modelo vertical autoritario". Se trata de una categoría general para describir el proyecto refundacional de las sociedades latinoamericanas llevado a cabo por las dictaduras cívico-militares, en el marco de la reorganización más amplia del capitalismo tardío dependiente. Su tesis organizadora es la de la ingobernabilidad de la democracia, ${ }^{12}$ y su presencia en América Latina aparece como "emisión" imperialista a partir del golpe de estado en 1964 en Brasil. Las principales características de este modelo son:

- Una reorganización corporativa y verticalista de la sociedad civil, posibilitada por la destrucción del anterior tejido colectivista popular y relativamente horizontal. Debido al predominio de los medios corporativos de comunicación, en este proceso la deliberación pública termina siendo transformada en opinión pública (esto es, en un subproducto u output de esos mismos medios).

- La reconstrucción del Estado en torno a su rol subsidiario, que lo torna un aparato al servicio de las dinámicas de la competencia capitalista en el seno de su propio funcionamiento. Esto, en el marco de una transnacionalización económica dogmática, propia del determinismo de mercado de Hayek et al.

- La doctrina de seguridad nacional como ideología explícita de este Estado (Zavaleta considera esta doctrina como la dimensión "político-militar" de la tesis de la ingobernabilidad de la democracia), acompañada por una técnica o dispositivo específico: la utilización del terror para lograr ajustes ideológicos que avancen en la fragmentación y segmentación de la totalidad del horizonte de referencias. ${ }^{13}$

7 Si la tesis basal a esta reorganización estatal de alcance regional es la de la ingobernabilidad democrática, y el terror cuenta como uno de sus dispositivos, tenemos ya un eje sobre el cual la dictadura aparece como democracia: en la administración de esa ingobernabilidad por medio de la aplicación controlada de políticas de seguridad/ insegurización, para realizar ajustes ideológicos cruciales en la búsqueda del consentimiento mínimo (disciplinamiento) que, a su vez y bajo ciertas condiciones, permite la continuidad de la normalidad democrática. En sintonía con este diagnóstico, la modalidad fascista del estado neoliberal ha sido destacada por la intelectual y activista María Galindo para observar de la actual coyuntura boliviana, caracterizada como una "fase" que es a su vez una intensificación de la tendencia a la privatización de la política. Esta privatización es propia de la democracia neoliberal, pero en 
condiciones de excepción se ve reforzada por el uso (por parte del estado tanto como de las clases dominantes) del terror con el fin de convertir cuestionamientos y alternativas legítimas en violentas contraposiciones de fuerzas. ${ }^{14}$

En el caso chileno, ha sido destacado por Nicolas Fleet que uno de los elementos cíclicos de dicha normalidad es el de la presencia de una "clase a cargo". El concepto es de Nicos Poulanzas y remite al hecho de que el bloque dominante se ve mucho más expuesto a la deslegitimación cuando tiene que gobernar de modo directo (como ha sucedido en ambas administraciones del multimillonario Sebastián Piñera, en 20102014 y 2018-2022) que cuando existe una clase que lo reemplaza en esta función (la que vendría siendo la ex Concertación, conglomerado que expresa el pacto entre el socialismo renovado y la democracia cristiana). ${ }^{15}$

Ampliando la mirada por sobre el continente, y tomando en cuenta primero el caso de la aplicación sin éxito de una nueva política de shock neoliberal en Ecuador durante septiembre de 2019, y luego la combinación de levantamiento y represión en Chile y Bolivia, podemos visualizar de mejor modo la permanencia de la tesis de la ingobernabilidad democrática en el ideario de la derecha neoliberal. En Bolivia, el golpe de estado se nutrió de levantamientos transversales a todo el espectro político, los que junto a una paciente manipulación imperialista terminaron desestabilizar el gobierno del MAS y que esto fuera capitalizado por la derecha más reaccionaria, la que representa los intereses de la Medialuna oligarca y proimperialista. ${ }^{16}$ Pero se debe recordar que, si acaso alguna vez se descontinuó, la seguidilla de "golpes blandos" y procesos de desestabilización de gobiernos progresistas recomenzó el 2002 con el intento de golpe de estado al primer gobierno de Hugo Chávez en Venezuela, siguiendo desde entonces en modalidades menos canónicas pero igualmente efectivas en Haití el 2004, Bolivia el 2008 (fallido), Honduras el 2009, Ecuador el 2010 (fallido), Paraguay el 2012, Brasil el 2016, Venezuela, Nicaragua y Cuba el 2018 (fallidos), y ahora en Bolivia.

\section{Crisis neoliberal y momento constituyente}

En Chile, la declaración de guerra que Piñera hiciera el 20 de octubre contra el "enemigo interno" no hizo sino repetir, en registro de farsa, lo que Pinochet estableciera como tragedia hace casi cincuenta años. ${ }^{17}$ En este escenario, el momento a la lucha de masas en Chile ha venido demostrando un decidido impulso antagonista hacia el conjunto de la institucionalidad neoliberal, algo que ha dejado en cierta forma paralizados a los partidos de la izquierda chilena, tradicionales y nuevos. En su conjunto, esta izquierda ha demostrado escasa capacidad para sincronizar con el movimiento de masas que ha tomado la iniciativa por el tiempo en el cual las correlaciones de fuerza se tensionaron al máximo, sin que haya sido posible parlamentarizarlas por el sistema político. Pero más allá de la izquierda, el mismo rebasamiento parcial de la institucionalidad político-partidaria por parte de la movilización es lo que permite considerar el proceso como tendencialmente prerrevolucionario, incluso en su momento actual de congelamiento en la intensidad de la movilización y la concomitante recuperación por parte del poder instituido. Ese poder instituido, por lo demás, ha hecho uso de un enorme repertorio que va de la represión directa (en su aterradora multiplicidad de prácticas), ${ }^{18}$ el terror mediáticamente inducido (con comprobadas acciones de autosabotaje), la dilatación parlamentaria, el desabastecimiento planificado, los saqueos coordinados y otras 
técnicas similares; todo para mantener a parte de la población expectante del "retorno a la normalidad".

Después de meses de protesta continua, y sin que el gobierno haya ofrecido aún solución alguna al conflicto, es posible pensar que, en caso de sobrevivir a eso que Zavaleta llamara "estado social de fatiga", ${ }^{19}$ la movilización decantará hacia una contradicción aún más abierta. Contradicción entre, por un lado, las clases dominantes atrincheradas en un poder del estado que acentúa su momento fascista, y por el otro un movimiento destituyente y constituyente que, a través de distintas estrategias y con diferentes ritmos, despliega una suerte de totalización democratizadora que coincide con la noción zavaletiana de democracia como "autodeterminación de las masas". Porque, así como no fetichiza la idea de democracia, Zavaleta tampoco la reduce y confunde con la dictadura.

12 Antes bien, junto con identificar las distintas operaciones de representación política y epistemológica que realiza el Estado capitalista en nombre de la democracia, Zavaleta señala que el momento cúlmine o fundacional de la polisémica noción aparece con el movimiento histórico de autodeterminación de masas: "el principio de la autodeterminación define la manera en que ocurren todos los otros conceptos de la democracia". ${ }^{20}$ Se trata de un proceso creativo, constituyente y en sí mismo "constitutivo", no sujeto a las formas institucionales anteriores de la política. La idea central aquí es la de masas o multitudes, que son producto del encuentro entre diversas formaciones pertenecientes a diferentes temporalidades y memorias que, en situación de "normalidad", conviven de modo abigarrado y sin mucha combinación. En cambio, en situación de crisis la masa o multitud es el territorio en el cual las prácticas y memorias de esas clases populares y subalternas se apropian de la política, en un despliegue totalizador de acontecimientos democratizantes que abren de ese modo espacios de visibilidad, encuentro y potencial autoconocimiento que no se encuentran al alcance en otras circunstancias. Se habla entonces de estos "momentos constitutivos" como momentos de sobredeterminación y de primacía excepcional de la superestructura sobre la infraestructura, ${ }^{21}$ del hecho político con capacidad para actuar sobre la determinación socioeconómica. Ahora bien, y lejos de romantizar este tipo de momentos, nuestro autor recordaba frecuentemente que muchas veces tienen características profundamente regresivas y autoritarias, como el caso del nazismo alemán o, digamos, de la dictadura pinochetista chilena.

13 En Chile, movilización mostró un enorme potencial de profundización, a ser confirmado en un futuro cercano. Aun cuando sus términos no han sido acordados (presos desde hace meses en una negociación ad infinutum entre fuerzas parlamentarias), se ha instalado ya en el imaginario colectivo nacional que durante el 2020 habrá un proceso constituyente, que eventualmente permitirá poner fin a la Constitución de 1980. Esto ha sido posible gracias a los diversos llamados a la autoorganización popular que, desde el momento mismo del inconstitucional decreto de Estado de Emergencia el 20 de octubre por parte de Piñera, han tomado forma mayoritaria en las asambleas constituyentes autoconvocadas. La doble determinación de la agudización del ajuste neoliberal como respuesta a su crisis (motivo inmediato de la reacción popular espontánea ante nuevos incrementos en el costo de la vida) y la exacerbación del problema crónico de legitimación de la democracia tutelada (amplificado por el recurso a la salida militar y a la violación abierta de derechos humanos) logró despertar una reacción asociativa espontánea que promete 
recomponer de manera significativa un tejido colectivo demasiado dañado por casi cincuenta años de dictadura y democracia neoliberal.

Si tenemos en cuenta que las y los jóvenes que alcanzaron a participar de la política nacional en tiempos de Allende tienen hoy alrededor de 65 años, podemos dimensionar de mejor manera que el movimiento constituyente (y que se expresó en más de 300 asambleas realizadas en promedio cada semana en Chile) corresponde a un ejercicio inédito de participación democrática de alta intensidad, a contracorriente del carácter "tutelado" del marco político heredado. Autoconvocados principalmente en torno a criterios territoriales y temáticos, estos cabildos y asambleas han permitido retejer lazos y esbozar nuevos criterios de convivencia en comunidad, pero también han dejado en total evidencia las profundas diferencias existentes en el país. En este marco cobra razón lo señalado por Camila Vergara cuando dice que, tal como Chile ha sido un laboratorio neoliberal, existen también condiciones para que devenga un laboratorio de democracia popular. ${ }^{22}$

El desarrollo de esa voluntad destituyente y constituyente se vio asimismo acompañado por el despliegue de una multiplicidad de eso que Zavaleta llamada "estructuras de rebelión". ${ }^{23}$ Esta pluralidad de estructuras de rebelión coincide con la variopinta constelación de temporalidades yuxtapuestas que el momento ofrece, momento en que la inmediatez del alza de treinta pesos da paso a una temporalidad neoliberal de treinta años de supuesta democracia y de cincuenta desde el desmantelamiento del estado social de Allende, para alcanzar la larguísima duración colonial de quinientos años. ${ }^{24} \mathrm{La}$ propia crisis corresponde a una contracción temporal (o bien a una yuxtaposición de temporalidades) que vuelve posible a las masas verse y reconocerse como unidad semiespontánea de lo diverso en acción, lo que a su vez brinda un espacio de posibilidades para ejercer soberanía sobre su propio movimiento. Durante octubre y noviembre, en cierto sentido este proceso detuvo el tiempo Chile, mientras estas estructuras de rebelión respondían a los embates del Estado neoliberal y todo su repertorio de represión militar y brutalidad policial; de normalización del estado de excepción y lumpenización de la violencia popular; de neutralización de la escalada del conflicto y cooptación selectiva de demandas.

En este contexto de confrontación entre un poder instituido en disposición neofascista y un movimiento constituyente de alcances insospechados, puede tener valor concluir con una breve relectura de la problematización que hiciera Zavaleta acerca de la dualidad de poderes. Por supuesto, no se trata de afirmar en modo alguno la existencia (empírica o proyectada) de una situación de poder dual en Chile, ni mucho menos intentar en las escasas líneas que quedan un análisis de esta figura y su pretendida "aplicación". Se trata primero que todo de recuperar su valor como "metáfora" para repensar cuestiones sobre las aspiraciones y capacidades de un movimiento histórico (ese que solemos llamar "clase") al conocimiento y al poder. ${ }^{25}$

\section{La crisis como método: dualidad de poderes y epistemología de la crisis}

17 Como se indicó más arriba, El poder dual marca la incorporación de Zavaleta al universo teórico del marxismo. Siguiendo la inspiradora lectura de Susana Draper, la apropiación zavaletiana del marxismo a través de la figura de la dualidad de poderes marca un límite (digamos, el del marxismo "a secas", como unidad transparente de 
método), y en consecuencia abre la pregunta epistemológica crucial para pensar la posibilidad de un marxismo latinoamericano. En uno de los textos más iluminadores (pero aún inédito) acerca de la dualidad de poderes en Zavaleta, Draper señala que esta problemática identifica un nodo crítico para pensar la noción de clase como subjetividad histórica (asociada de modo demasiado automático con el movimiento obrero) al mismo tiempo que replantea la concepción de desarrollo, y por ende de tiempo histórico, que guía la política de esta clase (normalmente entendido en un sentido linear y ascendente, como modernización industrializadora). ${ }^{26}$

Este modo de problematizar clase y conocimiento es el que Zavaleta pone en acción inmediatamente después de concluir El poder dual. ${ }^{27}$ Utilizando aquí uno de los subtítulos del artículo "Las masas en noviembre" (que fuera uno de su últimos escritos), propongo denominar a esta apertura "crisis como método". Se trata de considerar la crisis como espacio de autoaprendizaje práctico, concreto, cotidiano, de una subjetividad que en tanto unidad es en principio virtual (el pueblo, la clase, los subalternos, o la multitud como síntesis sin dialéctica de lo anterior), y que busca en este mismo momento crítico, y de modo antes práctico que teórico, adoptar definiciones que le permiten actualizar esa virtualidad. Porque para Zavaleta "[l]a multitud es la forma modificada de la clase", ${ }^{28} \mathrm{o}$ el movimiento por el cual la clase se actualiza históricamente en sus múltiples determinaciones, temporalidades y estructuras constitutivas, es que se hace necesario para el historiador materialista un método que considere la historia en tiempo presente. En otras palabras, los momentos de crisis permiten a las clases populares de sociedades abigarradas conocerse mejor:

A contrapelo [del tiempo normal], la historia, como economía, como política y como mito, se ofrece como algo centrado en la crisis. [...] La crisis es la forma de la unidad patética de lo diverso, así como el mercado es la concurrencia rutinaria de lo diverso. El tiempo mismo de los factores (y la principal diferencia entre un modo de producción y otro es la calidad del tiempo humano) no actúa de un modo continuo y confluyente, sino en su manifestación crítica. [...] El único tiempo común a todas estas formas es la crisis general que las cubre, o sea la política. ${ }^{29}$

En este párrafo podemos leer mejor la combinación posible de la noción de sobredeterminación (como unidad patética, ligada al pathos del momento crítico) con la imagen de una potencial apertura epistemológica que permita repensar las condiciones de unificación de la clase como sujeto histórico. Si consideramos la crisis chilena a partir de dos ejes de determinación (por un lado, la presión creciente sobre la reproducción general de la vida provocado por la austeridad neoliberal, y por el otro la baja calidad de la democracia representativa enmarcada en una constitución ilegítima) entenderemos por qué el fin del neoliberalismo y su sistema de desposesiones y abusos se identifica tan firmemente en esta coyuntura con la superación de la Constitución de 1980. Se trata de un momento en que lo que se ha puesto en cuestión es la coimplicación entre estructura económica y aparato estatal, y que por lo tanto ha irrumpido como contestación general hacia el modo de vida organizado bajo la temporalidad del capital y el estado. A su vez, esto torna visibles las estructuras y formas de temporalización que caracterizan hoy a las multitudes que habitan Chile, permitiendo visualizar algunas facetas en la composición de "la clase". ${ }^{30}$ Arriesgo aquí una lectura posible del escenario epistemológico abierto por la crisis chilena, distinguiendo en ellos tres grandes formaciones sociales que convergen en disposición subalterna y antagónica al poder instituido, y que sin embargo aún carecen de sincronización entre ellos. 
20 En primer lugar, se han producido avances indudables en la rearticulación de un movimiento de trabajadoras y trabajadores nacional y clasista. Con todas las debilidades de un movimiento obrero que cuenta en la actualidad con tasas de sindicalización cercanas al 20\%, y siendo la huelga efectiva y la negociación por rama ilegales en el país, la formación en el transcurso de la revuelta de un "bloque sindical" que agrupa a distintas expresiones de trabajadores organizados (y que ha llamado a dos huelgas generales en lo que va de conflicto) es una señal alentadora, si bien aún incipiente. Juega en contra el hecho de que muchas de estas organizaciones son controladas por burocracias sindicales ligadas a operaciones de partidos políticos que generalmente buscan la contención de sus bases antes que mayores niveles de organización y de audacia en la ofensiva antiausteridad. Pendiente queda en este plano la articulación de los sectores clásicos de los trabajadores organizados (estatales, portuarios, y de ramas estratégicas como la del cobre) con los esfuerzos de organización en sectores con otras condiciones de precarización laboral como los sectores retail, de servicios y el trabajo a honorarios.

21 En segundo lugar, el movimiento de autodeterminación popular ha tenido un capítulo especial en lo que parece ser un nuevo momento en la larga lucha del pueblo Mapuche. Esto, no solo por la creciente presencia de sus reivindicaciones generales (llamados a huelga general "plurinacional") y algunos de sus símbolos (banderas y otros) en las mismas movilizaciones, alcanzando incluso la incorporación de la demanda por escaños reservados en una eventual asamblea constituyente efectivamente plurinacional. Además, la toma de consciencia por parte del pueblo chileno acerca de las violaciones sistemáticas a los derechos humanos del estado neocolonial en territorio ancestral Mapuche (Wallmapu) ha dado al conflicto actual un marco temporal de largo alcance, además de poner en evidencia que este estado es desde el comienzo (y por ende durante toda su fase "democrática") incompatible con los derechos humanos. Más importante tal vez, el pueblo Mapuche ha iniciado llamados a generar instancias de autogobierno, en lo que puede proyectarse como el comienzo fáctico, histórico, de un ejercicio de autodeterminación que, aun habiendo sido ratificado por el estado de Chile desde 2007, ha sido anulado sistemáticamente por ese mismo estado para todos los efectos prácticos, en plena consonancia con la definición de uninacionalidad provista por la Constitución vigente. Partiendo por el cumplimiento de las demandas de desmilitarización inmediata del Wallmapu y respeto al derecho a la autodeterminación, seguramente estos espacios de deliberación autónoma traerán también nociones alternativas de soberanía y desarrollo, de las cuales los demás pueblos de Chile podemos y debemos aprender. ${ }^{31}$

Finalmente, la potencia feminista se ha manifestado de modo sostenido desde la irrupción de las movilizaciones, con presencia en forma de huelga de masas en las calles, despliegues culturales, denuncia y despliegue de formas de cuidado y rescatadas de la memoria popular de resistencia, cuyo ejemplo mayor son las ollas comunes que se vienen replicando de modo dramático en tiempos de pandemia. ${ }^{32}$ Continuando en parte con el impulso del "mayo feminista" de 2018, los feminismos entienden que el momento de crisis neoliberal es también de desestabilización patriarcal, pero asumen también que una restauración de ese poder patriarcal traerá consigo una aplicación mayor de la fuerza estatal, al mismo tiempo sobre los cuerpos (sobre todo los cuerpos feminizados y racializados) y sobre las subjetividades disidentes. Para Verónica Gago, el movimiento feminista chileno está mostrando la potencia de la yuxtaposición de la temporalidad 
estratégica (la del objetivo final) con su despliegue en tiempo presente, como política cotidiana inescapable para alcanzar la primera. ${ }^{33}$ Parte de las demandas se concentren en una nueva constitución que incorpore el género y los feminismos no solo en el texto, sino en la reorganización total del aparato estatal. ${ }^{34} \mathrm{Y}$, de cualquier modo, la política del cuidado que caracteriza a los feminismos debiese jugar un rol central en la contención de la "fatiga" que afecte a las multitudes en su dinámica emancipadora. La crisis actual multisistémica (económica, ecológica, política, cultural) permite distinguir mejor no solo la magnitud de la violencia neoliberal (expresada como momento fascista del estado), sino también y principalmente la composición real, histórica de las multitudes populares que avanzan hacia la superación del capitalismo en su fase actual. De la capacidad de escucha, articulación y sincronización entre esas tres formas de subjetivación y temporalización de la política, es decir, de esos tres desplazamientos de la "clase", dependerá la posibilidad de un nuevo bloque histórico con capacidad destituyente y constituyente, capaz de devolver el poder a las comunidades y pueblos que habitan Chile.

\section{NOTAS}

1. Este artículo fue escrito en lo fundamental a comienzos de 2020, y antes de su publicación sus referencias temporales fueron actualizadas.

2. "Chile, por lo menos aquel que llamamos el país oficial, fue siempre una tierra de frontera, un país construido contra los indios y en guerra con ellos," René Zavaleta, El poder dual. Problemas de la teoría del estado en América Latina, Ciudad de Mexico, Siglo veintiuno editores, 1974, p. 249.

3. Ver a este respecto José Aricó (ed.), Mariátegui y los orígenes del marxismo latinoamericano, Ciudad de México, Ediciones Pasado y Presente: distribuido por Siglo veintiuno editores, 1978; Raúl Fornet-Betancourt, Transformaciones del marxismo: historia del marxismo en América Latina, Nuevo León, Universidad Autónoma de Nuevo León, 2001; Omar Acha y Debora D’Antonio, “Cartografía y perspectivas del marxismo latinoamericano," en Carlos Aguirre (ed.), Militantes, intelectuales y revolucionarios. Ensayos sobre marxismo e izquierda en América Latina, North Carolina, A Contracorriente, 2013, pp. 181-228.

4. Por ejemplo, en René Zavaleta, "La burguesía incompleta," en Obra Completa. Tomo II. Ensayos 1975-1984, La Paz, Plural Editores, 2013. Para un desarrollo similar y contemporáneo al de Zavaleta, ver Bolívar Echeverría, "El problema de la nación (desde la 'crítica de la economía política')," Cuadernos Politicos, no. 29, 1981, pp. 25-35.

5. René Zavaleta, "Notas sobre fascismo, dictadura y coyuntura de disolución," en La Autodeterminación de Las Masas, Buenos Aires, Siglo veintiuno editores/CLACSO, 2015, p. 378.

6. Sigo parcialmente en estas notas el razonamiento de Enzo Traverso, quien previene de la tentación de transformar evaluaciones morales en categorías cognitivas de la política, y recalca lo insuficiente pero sin embargo indispensable que resulta ser la noción de "fascismo" en el escenario actual: "Pensar el fascismo hoy en día significa tomar en consideración las formas posibles de un fascismo del siglo XXI, no la reproducción de aquel que existió en la entreguerra", en Enzo Traverso, "Espectros del fascismo. Pensar las derechas radicales en el siglo XXI," MarxismoCritico.Com (blog), 6 de septiembre, 2019, http://marxismocritico.com/2016/09/06/ espectros-del-fascismo-pensar-las-derechas-radicales-en-el-siglo-xxi/. 
7. Estos incluyen al movimiento por el fin del sistema de pensiones con capitalización individual, de amplio apoyo ciudadano; el movimiento feminista que, en pocos años, ha recreado parte del tejido social y de la memoria colectiva del movimiento de mujeres y disidencias sexuales de los ochentas; y una serie de movimientos y organizaciones por la defensa y recuperación de ecosistemas vitales para nuestra futura reproducción, del que el movimiento Mapuche ha sido parte central desde hace décadas.

8. En los primeros dos meses de revuelta 22 personas fueron asesinadas por fuerzas del estado, alrededor de 3400 fueron heridas (casi dos mil por disparo, de las cuales 357 quedaron con daño ocular parcial o total producto de balines en el rostro), y más de 8 mil detenidas. Para los datos actualizados, ver el sitio web del Instituto Nacional de Derechos Humanos de Chile, www.indh.cl.

9. Ver David Harvey, El nuevo imperialismo, Madrid, Akal, 2004; David Harvey, Breve historia del neoliberalismo, Madrid, Akal, 2007; Naomi Klein, La doctrina del shock. El auge del capitalismo del desastre, Buenos Aires, Paidos, 2007; Jamie Peck, Constructions of Neoliberal Reason, Oxford, Oxford University Press, 2010; Jamie Peck, Nik Theodore, and Neil Brenner, "Postneoliberalism and Its Malcontents," Antipode 41, no. 1, 2010, pp. 94-116; Tomás Undurraga, Divergencias. Trayectorias del neoliberalismo en Argentina y Chile, Santiago de Chile, Ediciones Universidad Diego Portales, 2014.

10. Zavaleta, "Notas sobre fascismo, dictadura y coyuntura de disolución," p. 382.

11. Zavaleta, p. 373.

12. Ver principalmente el documento de Michel Crozier, Samuel Huntington, and Joji Watanuki, The Crisis of Democracy. Report on the Governability of Democracies to the Trilateral Commission, New York, New York University Press, 1975, http://archive.org/details/TheCrisisOfDemocracyTrilateralCommission-1975. Este es un documento geopolítico fundamental para comprender la convergencia de doctrinas acerca de "seguridad militar, desarrollo económico y democracia política” (Crozier, Huntington, and Watanuki, 1.) que serían luego características de los estados neoliberales latinoamericanos.

13. René Zavaleta, "Problemas de la determinación dependiente y la forma primordial," en La autodeterminación de las masas, Buenos Aires, Siglo veintiuno editores/CLACSO, 2015, pp. 300-304.

14. María Galindo, "Bolivia: la noche de los cristales rotos," LaVaca.Org (blog), 11 de noviembre, 2019, https://www.lavaca.org/notas/bolivia-la-noche-de-los-cristales-rotos-por-maria-galindo/.

15. Nicolas Fleet, "Protesta social y crisis del poder neoliberal en Chile 2011-2019," Pléyade. Revista de humanidades y ciencias sociales. Online (blog), 31 de octubre, 2019, http:// www.revistapleyade.cl/protesta-social-y-crisis-del-poder-neoliberal-en-chile-2011-2019/.

16. Ver Olivia Arigho-Stiles y Linda Farthing, "Bolivia's Tragic Turmoil," NACLA, 15 de noviembre, 2019, https://nacla.org/news/2019/11/15/Bolivia-Morales-Camacho; tambien Robert Cavooris, "Origins of the Crisis: On the Coup in Bolivia," ViewpointMagazine.Com (blog), 18 de noviembre, 2019, http://viewpointmag.com/2019/11/18/origins-of-the-crisis-on-the-coup-inbolivia/.

17. "La resistencia marxista no ha terminado, aún quedan extremistas. Yo debo manifestar que Chile está en este momento en estado de guerra interna". Citado en Verónica Valdivia Ortiz De Zárate, “‘ ¡Estamos en guerra, señores!'. El régimen militar de Pinochet y el 'pueblo', 1973-1980,” Historia 43, no. I, 2010, pp. 166-67.

18. Las dos prácticas disuasivas que mayor impacto han tenido durante la movilización han sido la violación de los detenidos (hombres y, en su gran mayoría, mujeres y personas de la comunidad LGTBQ+) por parte de personal policial, y el disparo de balines a los ojos de manifestantes por parte de esos mismos policías.

19. Ver René Zavaleta, "El estado en America Latina," en La autodeterminación de las masas, Buenos Aires, Siglo veintiuno editores/CLACSO, 2015, p. 315; también Raquel Gutiérrez Aguilar, "Bolivia: Statisation of the Social, Destruction of the Communitarian," Postcolonial Studies 22, no. 3, 3 de julio, 2019, pp. 283-92. 
20. René Zavaleta, "Cuatro conceptos de la democracia," en La autodeterminación de las masas, Buenos Aires, Siglo veintiuno editores/CLACSO, 2015, p. 141. Zavaleta describe un doble pliegue del concepto moderno de democracia. El primero es el pliegue o tensión ente la democracia como hecho económico-social (como liberación original de la concurrencia al mercado por parte de la fuerza de trabajo) y como hecho estatal (como monopolización de la política por vía de su autonomización relativa). Este último, a su vez, sufre un segundo pliegue entre el aspecto liberal o clásico de la representación como presencia (o representación como el lugar del "hablar por", en la lectura de Spivak), por un lado, y su rol gnoseológico o de producción de subjetividad y de objeto de discurso (representación como "hablar de"), por el otro. Ver también Gayatri Chakravorty Spivak, "Can the Subaltern Speak?," en Cary Nelson y Lawrence Grossberg (eds.), Marxism and the Interpretation of Culture, Basingstoke, Macmillan Education, 1988.

21. En la conceptualización de Zavaleta, estos dos aspectos o momentos se encuentran en una situación de simultaneidad topológica, es decir, en una relación que $\mathrm{n}$ resiste la metáfora arquitectónica de infra y super, y que es más parecida a la de círculos concéntricos y en cierto sentido sobrepuestos. Ver Mauricio Gil, “Zavaleta Mercado. Ensayo de biografía intelectual," en Maya Aguiluz Ibargüen y Norma de los Ríos Méndez (eds.), René Zavaleta Mercado. Ensayos, testimonios y re-visiones, Buenos Aires, Miño y Dávila, 2006, pp. 93-110.

22. Camila Vergara, "Chile Can Be a Laboratory of Popular Democracy," Jacobin, 23 de noviembre, 2019, https://jacobinmag.com/2019/11/chile-protests-pinochet-constitution-neoliberalism.

23. "La historia de las masas es siempre una historia que se hace contra el Estado, de suerte que aquí hablamos de estructuras de rebelión y no de formas de pertenencia", Zavaleta, "Cuatro conceptos de democracia", Zavaleta, "Cuatro Conceptos de La Democracia," p. 138. En lo que va del conflicto chileno, estas formas van desde la autodefensa barrial y callejera a la movilización masiva en las principales calles de las principales ciudades; despliegues culturales populares y de desobediencia civil, sea para evadir el cobro en el transporte o para desafiar el toque de queda; asambleas locales y caminatas o cicletadas masivas, incluso entre ciudades distantes; ollas comunes populares, bloqueo de puntos estratégicos y paralización de faenas; múltiples "cacerolazos" en distintos puntos de protesta y dos jornadas de huelga general plurinacional.

24. Herson Huinca-Piutrin, “'No son 30 pesos. Son 500 años': Los pueblos indígenas hacia la constitución de un Estado plurinacional," Pléyade. Revista de humanidades y ciencias sociales. Online (blog), 31 de octubre, 2019, http://www.revistapleyade.cl/no-son-30-pesos-son-500-anos-lospueblos-indigenas-hacia-la-constitucion-de-un-estado-plurinacional/. Sería interesante poner en relación estas estructuras pluritemporales con la noción de Ernst Bloch de "no contemporaneidad" con la que analiza la emergencia de formaciones fascistas en la Europa de entreguerras, algo que por razones de espacio no podemos abarcar en este escrito. Ver sin embargo Ernst Bloch, "Nonsynchronism and the Obligation of Its Dialectics," New German Critique, no. 11, 1977, pp. 22-38. Ver también el sugerente ensayo de Alberto Toscano, "Notes on Late Fascism," HistoricalMaterialism.Org (blog), 2 de abril, 2017, http://www.historicalmaterialism.org/ blog/notes-late-fascism (una traducción mía de este ensayo se encuentra pronto a aparecer en español, en el volumen 25 de Pléyade. Revista de humanidades y ciencias sociales).

25. Sobre la relación de Zavaleta y la "metáfora" de la dualidad de poderes, ver Claudio Aguayo Bórquez, "Zavaleta Mercado y la metáfora en el texto marxista," Observatorio Latinoamericano y Caribeño 3, no. 1, 2019, pp. 22-39.

26. Susana Draper, "Re-Reading the Heterodox Marxist Canon: René Zavaleta Mercado on Dual Power and Other Marxist Metaphors of State Transformation in Latin America", inédito, n/d, https://www.academia.edu/7580853/Re-

reading_the_heterodox_marxist_canon_Ren\%C3\%A9_Zavaleta_Mercado_on_dual_power_and_other_marxist_metaphors_of_state_tra 27. En una trayectoria que parte con una reflexión, digamos, lukacsiana: René Zavaleta, "Clase y conocimiento," en La autodeterminación de las masas, México D.F. y Buenos Aires, Siglo veintiuno editores - CLACSO, 2015, pp. 67-76. 
28. René Zavaleta Mercado, "Las masas en noviembre," in La autodeterminación de las masas, Ciudad de México y Buenos Aires, Grupo editorial Siglo XXI - CLACSO, 2015, p. 220; también "Forma clase y forma multitud en el proletariado minero en Bolivia," en La autodeterminación de las masas, Buenos Aires, Siglo veintiuno editores/CLACSO, 2015.

29. Zavaleta Mercado, "Las masas en noviembre," p. 216.

30. Me baso en la lectura que hace Domenico Losurdo del concepto de "luchas de clases", que el autor considera que contiene desde el comienzo su pluralización, y desde el cual ya Marx ofrecería al menos tres coordenadas o ejes de contradicción de clase: capital/trabajo, impero/ colonia, y señorío y servidumbre doméstica dentro de la institución del matrimonio. Por lo tanto, la "clase" en singular contendría desde el comienzo (al menos virtualmente) su pluralización en tres rostros: el del obrero, el de la mujer y el de colonizado o indígena. Ver Domenico Losurdo, Class Struggle: A Political and Philosophical History, Marx, Engels, and Marxisms, New York: Palgrave Macmillan, 2016.

31. Ver Sergio Caniuqueo Huircapan, "Pueblo Mapuche y la inflexión histórica del 18/0," Mapuexpress (blog), 1 de noviembre, 2019, https://www.mapuexpress.org/2019/11/01/pueblomapuche-y-la-inflexion-historica-del-18-o/; "Dirigentes Mapuche se reúnen en el Ñielol para avanzar en 'autogobierno mapuche' | Mapuexpress," accessed December 11, 2019, https:// www.mapuexpress.org/2019/12/11/dirigentes-mapuche-se-reunen-en-el-nielol-para-avanzaren-autogobierno-mapuche/.

32. Diego Rivera, “Chile's 'Olla Común' Through History," chiletoday.cl, 28 de mayo, 2020, https://chiletoday.cl/site/chiles-olla-comun-through-history/.

33. Verónica Gago, "Realpolitik revolucionaria," ctxt.es | Contexto y Acción, 1 de noviembre, 2019, http://ctxt.es/es/20191030/Firmas/29258/realpolitik-feminismo-revolucion-feministachile-veronica-gago.htm.

34. Barbara Sepúlveda and Lieta Vivaldi, “Algunas reflexiones feministas en la revuelta," Pléyade. Revista de humanidades y ciencias sociales. Online (blog), 11 de noviembre, 2019, http:// www.revistapleyade.cl/algunas-reflexiones-feministas-en-la-revuelta/.

\section{RESÚMENES}

El mapa sociopolítico latinoamericano ha venido transformándose en las últimas semanas, y la imagen de la franja andina en un proceso de ajuste de placas tectónicas promete que el ciclo de revueltas adquiera alcances continentales: hoy muestra su epicentro en Estados Unidos tal y como lo hiciera meses atrás en Ecuador, Chile, Bolivia y Colombia. Este artículo analiza el proceso chileno, haciendo referencias acotadas al proceso boliviano y al resto del continente, y discutiendo para estos efectos de las propuestas teóricas del marxista boliviano René Zavaleta Mercado. En particular, traemos sus reflexiones sobre el fascismo en el contexto del capitalismo dependiente, los procesos de autodeterminación democrática, y la revisión de la noción de dualidad de poderes, especialmente en lo que respecta a sus alcances epistemológicos.

Latin America's sociopolitical map has been recently transformed, and the image of the Andean belt in a process of tectonic plates' adjustment promises the cycle of revolt to have continental scope; today, it displays its epicenter in the United States as it did months ago in Ecuador, Bolivia, Chile and Colombia. This article analyzes the Chilean process, with bounded remarks to the Bolivian events and to the rest of the continent, and to do so it discusses the theoretical 
propositions of Bolivian Marxist René Zavaleta Mercado. More concretely, I bring his reflections about fascism in the context of dependent capitalism, the self-determination processes, and his revision of the notion of duality of powers, especially in what refers to the latter's epistemological scope.

\section{AUTOR}

\section{FELIPE LAGOS-ROJAS}

Investigador y Coordinador del Programa de investigación en Críticas Latinoamericanas del Instituto Internacional para la Filosofía y los Estudios Sociales IIPSS. Profesor de Comunicación Intercultural en la Universidad de O'higgins, Chile. Doctor en sociología por Goldsmiths College, University of London. Sociologo y magister en estudios latinoamericanos por la Universidad de Chile. Recientemente coeditó el libro Latin American Marxisms in Context: Past and Present, Cambridge, Cambridge Publishers, 2019, y autor de un capitulo en el mismo, además de autor de otros artículos sobre pensamiento crítico latinoamericano, racismo, colonialismo e indigeneidad en las Américas, y teoría crítica. Correo electrónico: flagos@iipss.com

Researcher and Coordinator of the Latin American Critiques Research Program of the International Institute for Philosophy and Social Studies IIPSS. Instructor of Intercultural Communication in the Universidad de O'higgins, Chile. Doctor in Sociology at Goldsmiths College, University of London, and sociologist and master in Latin American Studies at the Universidad de Chile. He recently co-edited the volume Latin American Marxisms in Context: Past and Present, Cambridge, Cambridge Publishers, 2019, and authored one of its chapters. He has also written articles about Latin American critical thinking, racism, colonialism and indigeneity in the Americas, and critical theory. Email: flagos@iipss.com. 